\title{
Obituary: John Bensted
}

It is with great regret that we report the death of Professor John Bensted on the 12th of November 2019 aged 77 years.

John was an extraordinarily talented man, having graduated in chemistry in 1964, he then completed his PhD in 1968 and DSc in 1981. He combined chemistry with engineering, academe with application. His specialist interests covered cement and materials science coupled with relevant applications and problem solving for some 45 years.

John was a prolific publisher and communicator with over 500 peerreviewed papers and over 100 conference presentations. He was a leading contributor to the Society of the Chemical Industry and was awarded the Lampitt medal in 2010. This is the highest award that the Science Citation Index can give. He was honoured with no less than three visiting professorships at Birkbeck College (University of London), University of Greenwich and Keele University - a fitting tribute to his quite unique contribution to the fields of cement, concrete, and gas and oil exploration. He spent periods with Blue Circle Industries and BP International Ltd (with time spent in the USA, Brazil, Venezuela, and Western and Eastern Europe).

John was a Fellow of the Royal Society of Chemistry and the Institute of Materials, Minerals and Mining, and was also a chartered chemist, scientist and engineer.

He was a thinker, researcher, writer, examiner and lecturer. His multidisciplinary expertise combined with his lateral thinking and troubleshooting skills resulted in numerous valuable contributions to the cement, construction and oil industries.

John was from a disappearing generation of committed knowledgegatherers and expert practitioners and will be very difficult to replace. Our deepest regards go to his wife Josephine Marian, his two sons, Jonny and Roland, and daughter-in-law, Jiyceon.

Peter Hewlett

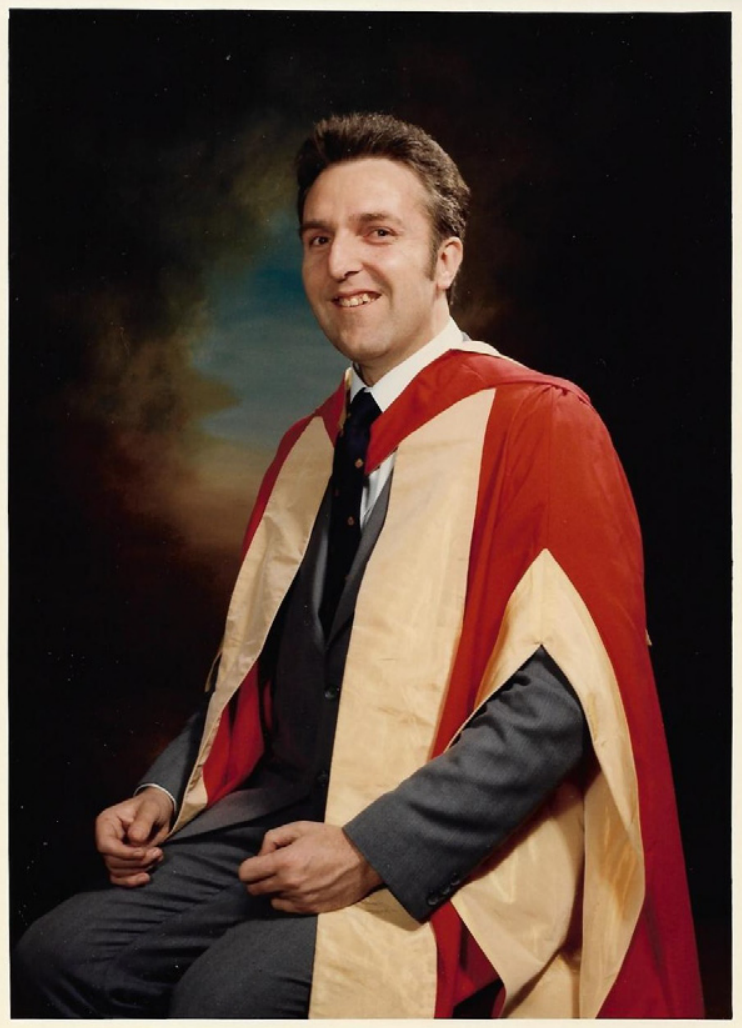

John Bensted, 1942-2019 